\title{
Development and characterization of biocompatible isotropic and anisotropic oil-in-water colloidal dispersions as a new delivery system for methyl dihydrojasmonate antitumor drug
}

This article was published in the following Dove Press journal:

International Journal of Nanomedicine

II February 2014

Number of times this article has been viewed

\section{Gisela Bevilacqua Rolfsen \\ Ferreira da Silva' \\ Maria Virginia Scarpa' \\ Gustavo Rossanezi' \\ Eryvaldo Socrates Tabosa \\ do Egito 2 \\ Anselmo Gomes de \\ Oliveira'}

'Departamento de Fármacos e Medicamentos, Universidade Estadual Paulista (UNESP),

Araraquara, SP, Brazil; ${ }^{2}$ Laboratório de Sistemas Dispersos, Universidade Federal do Rio Grande do Norte (UFRN) Natal, RN, Brazil
Correspondence: Anselmo Gomes de Oliveira

Departamento de Fármacos e Medicamentos, Faculdade de Ciências Farmacêuticas, Universidade Estadual Paulista (UNESP), Rodovia Araraquara-Jaú Km 0I, Araraquara, SP I480 I-902, Brazil

Tel +55 I6 330l 6974

Fax +55 I6 330I 6960

Email oliveiag@fcfar.unesp.br

\begin{abstract}
Microemulsions (MEs) are colloidal systems that can be used for drug-delivery and drug-targeting purposes. These systems are able to incorporate drugs modifying bioavailability and stability and reducing toxic effects. The jasmonate compounds belong to a group of plant stress hormones, and the jasmonic acid and its methyl ester derivative have been described as having anticancer activity. However, these compounds are very poorly water-soluble, not allowing administration by an intravenous route without an efficient nanostructured carrier system. In this work, biocompatible MEs of appropriate diameter size for intravenous route administration, loaded and unloaded with methyl dihydrojasmonate (MJ), were developed and described in a pseudo-ternary phase diagram. The compositions of the MEs were carefully selected from their own regions in the pseudo-ternary phase diagram. The formulations were analyzed by light scattering, polarized light microscopy, and X-ray diffraction. Also, a study on rheological profile was performed. The results showed that the droplet size decreased with both MJ incorporation and oil phase/surfactant ratio. All compositions of the studied MEs showed rheological behavior of pseudoplastic fluid and amorphous structures. In the absence of MJ, most of the studied MEs had thixotropic characteristics, which became antithixotropic in the presence of the drug. Almost all MJ-unloaded MEs presented anisotropic characteristics, but some formulations became isotropic, especially in the presence of MJ. The results of this study support the conclusion that the studied system represents a promising vehicle for in vivo administration of the MJ antitumor drug.
\end{abstract}

Keywords: methyl dihydrojasmonate, anticancer drug, biocompatible microemulsions, pseudoternary phase diagram, microemulsion characterization

\section{Introduction}

Microemulsions (MEs) are colloidal systems that can be used for drug-delivery and drug-targeting purposes. These aggregates are able to incorporate drugs modifying bioavailability and stability and reducing toxic effects. ${ }^{1,2}$ MEs are clear, isotropic, and thermodynamically stable systems usually stabilized by surfactant-cosurfactant combinations. ${ }^{3-5}$ However, while maintaining the isotropic characteristic, the structural organization of such systems can be profoundly changed by varying the composition and concentration of stabilizer surfactants, by changing the rate of the oil phase, and by incorporating lipophilic drugs. ${ }^{6-8}$ 
Oil-in-water MEs are frequently used for intravenous administration of poorly water-soluble drugs, not only because they are able to incorporate lipophilic drug compounds but also because they have diameters of nanometer order, which implies a very large interfacial area. ${ }^{3-5,9}$ Antitumor and antibiotic drugs have often been incorporated into oil-in-water colloidal dispersions, due to the ability of such systems to reduce toxicity and increase therapeutic efficacy. $^{7-10}$

The jasmonates belong to a group of cyclopentenone moiety that is synthesized in plants in response to injury, insect attack, and wounding. ${ }^{11}$ Several reports have demonstrated that cyclopentenone moiety-containing molecules such as prostaglandins and clavulones induce apoptosis in different signaling mechanisms. ${ }^{12-14}$

Jasmonate-derivative compounds, including jasmonic acid (JA) and methyl dihydrojasmonate (MJ), have been reported to inhibit the growth of leukemia cells as well as lung, breast, and prostate cancer cells, and to produce in vivo anticancer activity. ${ }^{15,16}$ Different mechanisms have been proposed to explain the anticancer activity of jasmonate derivatives. Among them, the ability of MJ to open the mitocondrial permeability transition-pore complex, allowing cytochrome $\mathrm{C}$ release and induction of apoptosis, and the expression of reactive oxygen species are the most important ones. ${ }^{17-19}$ The induction of suppression of cell proliferation in human and mouse cancer cell lines, such as prostate cancer and breast cancers, melanoma, leukemia, lymphoid, and myeloid, has also been reported. Jasmonate presented selective cytotoxicity in cancer cells in patients with chronic lymphocytic leukemia, leaving the nontransformed cells intact. $^{19,20}$

These compounds are poorly water-soluble, and cannot be administered intravenously or adequately absorbed by the body. However, for MJ, there are no studies on delivery systems that could circumvent these problems. In the pharmaceutical technology field, systems based on the nanotechnology platform may increase the apparent solubility of poorly soluble drugs, improving bioavailability and providing safe administration in the body, especially nanoand microemulsion systems. ${ }^{5-10} \mathrm{MJ}$ derivatives follow the physicochemical characteristics of these compounds and cannot be directly administered, and it is necessary to develop systems for such administration.

Thus, the aim of this work was to produce MEs with and without MJ in order to improve the aqueous solubility of the drug. The systems were described in a pseudo-ternary phase diagram and characterized by light scattering, polarized light microscopy, X-ray diffraction, and rheological profile in order to obtain information about the nanostructured system and to evaluate the behavior of the formulations as a possible carrier for jasmonate derivatives used in anticancer therapy.

\section{Materials and methods Materials}

Soy phosphatidylcholine (PC; Chemical Abstracts Service [CAS] number 97281-47-5; Phospholipon ${ }^{\circledR}$ 90G) was purchased from Lipoid, Ludwigshafen, Germany. MJ (CAS number 24851-98-7), cholesterol (CHO; CAS number 57-88-5), and sodium oleate (SO; CAS number 143-19-1), were purchased from Sigma-Aldrich, St Louis, MO, USA. Tris(hydroxymethyl) aminomethane (CAS number 77-86-1) was purchased from Merck, Darmstadt, Germany. Polyoxyethylene glycerol trihydroxystearate 40 (Eumulgin ${ }^{\circledR}$ HRE 40 [EU], CAS number 61788-85-0) was purchased from Pharma Special, São Paulo, Brazil. Water was purified in a Milli-Q Plus purification system (Millipore, Billerica, MA, USA), and its resistivity was 18.2 M $\Omega-\mathrm{cm}$. All other chemicals and solvents used in this work were of analytical grade or better.

\section{Methods}

\section{Phase diagram}

The surfactant mixture (S) containing appropriated proportions of $\mathrm{PC} / \mathrm{EU} / \mathrm{SO}$ was previously established as 7:7:3 $(\mathrm{w} / \mathrm{w}) .{ }^{1,7}$ These stabilizers provided a clear system conceptually consistent with ME structure. The oil-phase $\mathrm{CHO}(\mathrm{O})$ was added over the semisolid surfactant mixture (S) in ratios of 1:9 and 9:1 (w/w) to obtain the pseudo-ternary phase diagram. Using a precision burette, the aqueous phase (W) was carefully dripped onto the $\mathrm{S}$ and $\mathrm{O}$ with constant homogenization. The regions of transition from semisolid mixture to clear systems and from clear to translucent colloidal systems were adequately reproducible within $0.05 \mathrm{~mL}$ of W. All determinations were realized at $25^{\circ} \mathrm{C} \pm 0.1^{\circ} \mathrm{C}$. For the systems containing $\mathrm{MJ}$, the drug was added to the $\mathrm{S} / \mathrm{O}$ mixture and the procedure was followed as described for MJ-unloaded systems.

\section{Microemulsion preparation}

The systems were prepared as previously described. ${ }^{21,22}$ Briefly, PC, EU, and SO were weighted and mixed to obtain $\mathrm{S}$. To the mixture of $\mathrm{S}$, an appropriate amount of $\mathrm{O}$ was added. To the mixture of $\mathrm{S}$ and $\mathrm{O}$, the aqueous phase was added. This sequence provides a complete homogenization of the components. Then, the system was kept under ultrasonic agitation in a discontinuous mode for 20 minutes 
(1 minute of sonication and 1-minute interval) in an ice bath. For the systems loaded with MJ, the drug was dissolved in systems already prepared. All formulations studied in this work are listed in Table 1.

\section{Dynamic light scattering}

The analysis was a performed with a dynamic light-scattering apparatus (EMI 9863; Brookhaven Instruments, Holtsville, NY, USA), with He-Ne $10 \mathrm{~mW}$ laser source at $532 \mathrm{~nm}$. For analysis, the samples were diluted with aqueous phase of the systems. The measurements were obtained with a fixed angle of $90^{\circ}$. The results represent the mean \pm the standard deviation of at least ten determinations. The analyses were carried out at $25^{\circ} \mathrm{C} \pm 0.2^{\circ} \mathrm{C}$.

\section{Rheological measurements}

The analyses were performed using a Carrimed CSL 100 rheometer (TA Instruments, New Castle, DE, USA) with cone-plate geometry: a $2^{\circ}$ stainless steel cone with a $4 \mathrm{~cm}$ diameter and a gap of $105 \mathrm{~mm}$ between the cone and plate.

The results were obtained with a shear rate $(\gamma)$ in the range of $0-300$ seconds $^{-1}$. Rheological analyses were performed for both the up and up-down curves. The data of the shear cycle were fitted to the power-law model using Rheology Solutions software (Data V1.1.7; TA Instruments). All determinations were realized in triplicate at $25^{\circ} \mathrm{C} \pm 0.2^{\circ} \mathrm{C}$.

\section{Polarized light microscopy}

ME samples were prepared by placing a drop of ME between a coverslip and a glass slide, and were then examined under polarized light. An optical microscope (Leica Microsystems, Wetzlar, Germany) equipped with a digital camera was used to analyze various fields of each sample at room temperature. The isotropic and anisotropic behavior of the samples was observed. Pictures were taken at 200× magnification.

\section{X-ray diffraction}

The crystalline structure of the samples was analyzed by powder X-ray diffraction. The data were collected on a

Table I Composition of the ME formulations used in this study

\begin{tabular}{llllll}
\hline Composition \% (w:w) & A & B & C & D & E \\
\hline PC/EU/SO (7:7:3) (S) & 20 & 20 & 20 & 20 & 20 \\
CHO (O) & 2 & 4 & 6 & 8 & 10 \\
Aqueous phase (W) & 78 & 76 & 74 & 72 & 70 \\
Methyl dihydrojasmonate (MJ) & 6 & 6 & 6 & 6 & 6 \\
O:S ratio & 0.1 & 0.2 & 0.3 & 0.4 & 0.5 \\
\hline
\end{tabular}

Abbreviations: ME, microemulsion; w:w, weight:weight; PC, phosphatidylcholine; EU, Eumulgin ${ }^{\circledR} \mathrm{HRE} 40$; SO, sodium oleate; CHO, cholesterol; S, surfactant; O, oil phase.
Siemens (Munich, Germany) D-500 diffractometer $(\mathrm{Cu} \mathrm{K} \alpha$ radiation, $\lambda=1.541 \AA$ ) with a curved graphite monochromator, by using the step-counting method (step $0.05^{\circ}$ and time 0.1 second) in a $2 \theta$ range between $4^{\circ}$ and $70^{\circ}$.

\section{Results and discussion}

The domain regions of the different systems obtained from the mixture of the formulation components are shown in the pseudo-ternary phase diagram of Figure 1, with (Figure 1A) and without (Figure 1B) MJ. In the absence of MJ, the liquid $\mathrm{ME}$ (LME) region was obtained above $70 \%$ of the aqueous phase with a surfactant range of $5 \%-30 \%$, and up to $10 \%$ of the oil phase. Regions such as gel MEs (GMEs), liquid emulsions (LEMs), gel emulsions (GEMs), and phase separation (PS) were also obtained. The phase-diagram profile changed with the presence of MJ. In fact, when MJ was incorporated within the system (Figure 1B), the GME region completely disappeared and the LEM region significantly increased. In the presence of $\mathrm{MJ}$, the LME region was characterized at above $65 \%$ of the water phase, up to $10 \%$ of the oil phase, and $35 \%$ of surfactants. In addition, LEM, GEM, and PS regions were found. Independently of the presence of MJ, the system became viscous when the proportion of the surfactant increased in the low-aqueous and high-oil phases. This phenomenon can be explained by the fact that the soy PC proportion of the surfactant mixture can absorb small amounts of water to form viscous gels. ${ }^{8}$

Because of the predominant lipophilic character of PC, which has a low hydrophilic lipophilic balance (HLB) value (4.0), high hydrophilic surfactants were associated with it to give an appropriated mix to stabilize the system. Thus, EU $(\mathrm{HLB}=14)$ and $\mathrm{SO}(\mathrm{HLB}=18)$ were used for this purpose of allowing greater absorption of the aqueous phase by the system.

Although the LME domain has been characterized by a limited region in the pseudo-ternary phase diagrams (Figure 1), the characteristics of transparency of the systems remained unchanged with infinite dilution with the water phase towards a swollen micelle system, as previously described in the literature. ${ }^{23-25}$

LME compositions were selected from the respective domain region (Figure 1) for the sequence of the study. The chosen formulations were titled A, B, C, D, and E, in which the proportion of the surfactant was kept constant at 20\% and the oil phase was increased from $2 \%$ to $10 \%$ in order to obtain $\mathrm{O}: \mathrm{S}$ ratios of $0.1,0.2,0.3,0.4$, and 0.5 , respectively (see Table 1 for details). The specific points were represented in the pseudo-ternary phase diagram (Figure 1). 


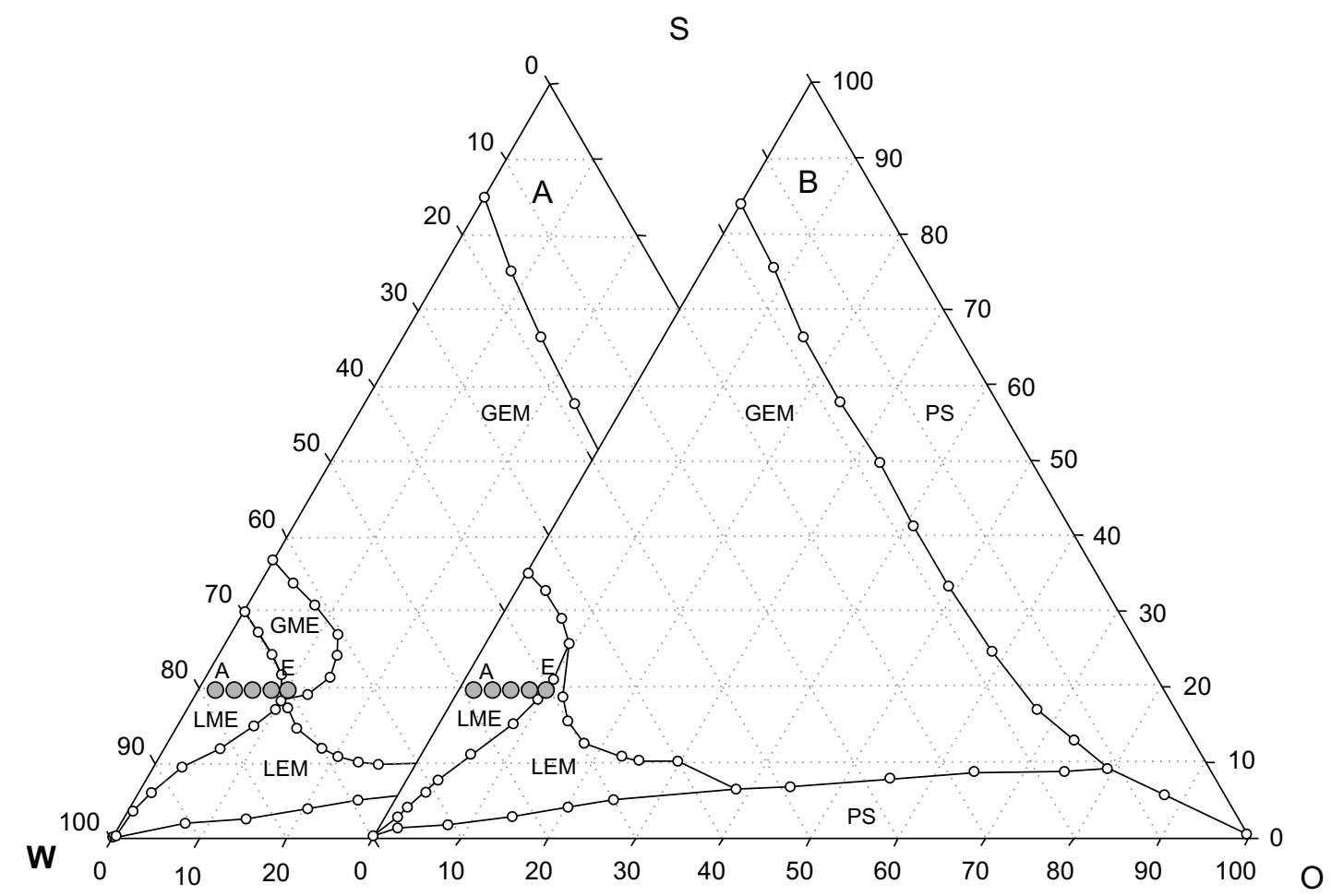

Figure I Pseudo-ternary phase diagram for the system containing, PC/EU/SO (S), CHO (O), and aqueous buffer (W). MJ-free diagram (A) and MJ-containing phase diagram (B).

Notes: Specific compositions of the studied MEs; O, phase-transition regions, $25^{\circ} \mathrm{C}$.

Abbreviations: PC, phosphatidylcholine; EU, Eumulgin ${ }^{\circledast}$ HRE 40; SO, sodium oleate; CHO, cholesterol; MJ, methyl dihydrojasmonate; LME, liquid microemulsion; GME, gel microemulsion; GEM, gel emulsion; LEM, liquid emulsion; PS, phase separation.

The water solubility of MJ calculated from the determination of the octanol/water partition coefficient (log $\mathrm{o} / \mathrm{w}=2.98$ ), at $25^{\circ} \mathrm{C}$ was $91.7 \mathrm{mg} / \mathrm{L}$, disclosing a compound having predominantly lipophilic character. It is well established that regardless of the electric charge of the carrier system for neutral drugs such as MJ, the incorporation process is driven by hydrophobic interactions between the molecule and the organized system. ${ }^{26,27}$ Considering the solubility characteristics of the MJ molecule, we assume that the fraction of drug remaining in the aqueous phase is negligible and that the drug is completely associated to the oil phase of ME. In fact, after centrifugation at 5,000 rpm for 15 minutes, no sedimentation or aggregation was observed. Accordingly, assuming negligible $\mathrm{MJ}$ water solubility and that the drug was completely incorporated into the ME system $(6 \% \mathrm{w} / \mathrm{w})$, an increase in the solubility of 600 -fold was found.

In this study, the maximum concentration of MJ that could be incorporated into the system while maintaining the clear characteristic of the colloidal dispersion was $6 \%(\mathrm{w} / \mathrm{w})$. Thus, for MJ-loaded MEs, this concentration was used in the LME region for the sequence of the study.

For both MJ-unloaded and MJ-loaded MEs, the effect of the oil phase/surfactant ratio $(\mathrm{O} / \mathrm{S})$ on the diameter of the
LME is shown in Figure 2. Independently of the presence of MJ, the diameter of the LME was highly dependent on the $\mathrm{O} / \mathrm{S}$ ratio, showing a bell-shaped curve reaching a maximum and decreasing sharply at a high $\mathrm{O} / \mathrm{S}$ ratio (Figure 2). Detailed results including the polydispersity index are shown in Table 2.

When the $\mathrm{O} / \mathrm{S}$ ratio was increased in the absence of MJ, the diameter of the oil droplets ranged from 160 to $180 \mathrm{~nm}$ at low $\mathrm{O} / \mathrm{S}$ values, decreasing thereafter to about $40 \mathrm{~nm}$, leading to a completely clear system. On the other hand, in the presence of MJ, the bell-shaped curve was less intense. The diameters increased from $56 \mathrm{~nm}$, reaching a maximum at around $80 \mathrm{~nm}$ and subsequently decreasing to values less than $20 \mathrm{~nm}$ at high $\mathrm{O} / \mathrm{S}$ ratios. This phenomenon may be related to the presence of $\mathrm{CHO}$ in the system, which has surfactant properties and may be distributed in the oil-water interface, contributing to the decrease in droplet diameter. ${ }^{8}$

On the other hand, it is also important to note that in addition to the large decrease in diameters in the presence of MJ, a difference in the maximum diameter region between the curves with no MJ was observed. This profile can be explained by the fact that although the drug exhibited hydrophobicity, the presence of the organic ester function 


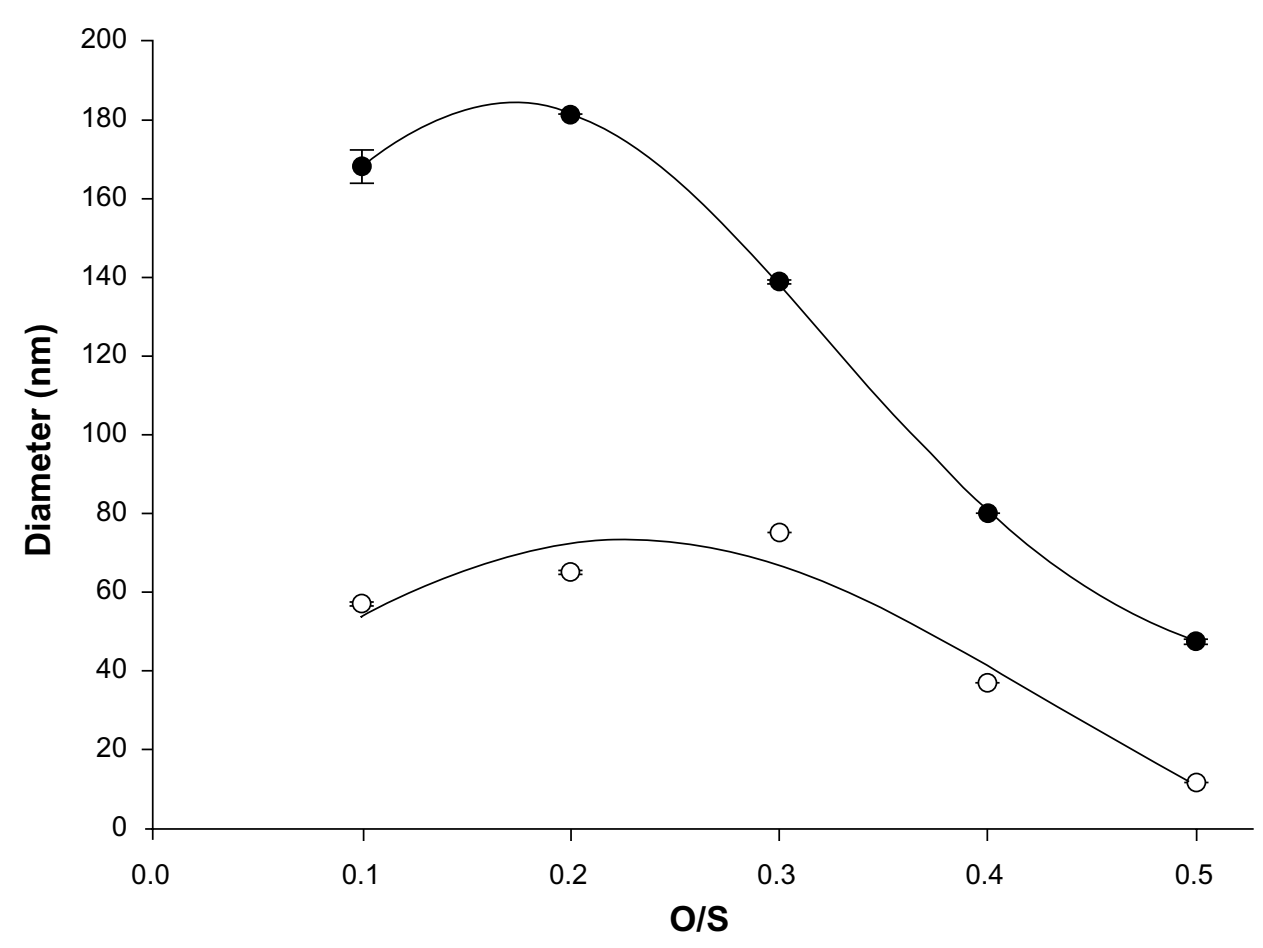

Figure 2 Effect of oil phase/surfactant (O/S) ratio on droplet diameter.

Notes: •, MJ-unloaded ME; O, MJ-loaded ME, $25^{\circ} \mathrm{C}$.

Abbreviations: $M J$, methyl dihydrojasmonate; ME, microemulsion.

also conferred to the molecule the property of a surfactant. Thus, the presence of the MJ bell-shaped profile was greatly minimized and shows an enlarged region of maximum diameter. Thus, as the drug also exhibited a small surfactant effect due to ester structure, the bell-shaped profile curve was minimized and slightly extended.

The data of Figure 2 show that MJ incorporation into the LME system led to a pronounced reduction in droplet diameter. The diameters varied from 170 to $57 \mathrm{~nm}$ at low $\mathrm{O} / \mathrm{S}$ ratios, and from 48 to about $20 \mathrm{~nm}$ at high $\mathrm{O} / \mathrm{S}$ ratios. This phenomenon can be explained by the fact that $\mathrm{MJ}$ is a methyl ester compound and a fraction of the drug may be organized in the oil-water interface, favoring the thermodynamic stability of LME and the decrease of the curvature radius of the oil droplets. Thus, as the diameters ranged from $20 \mathrm{~nm}$ up to $80 \mathrm{~nm}$ in the presence of MJ, it is possible to use these formulations by the intravenous route, as previously described.

The polydispersity index (Table 2) was calculated by the average size of the droplets divided by the average number of measured droplets. The polydispersity index obtained from the light-scattering analysis showed values from 0.07 to 0.3 , indicating a good size distribution of the oil droplets in the ME system. This parameter directly reflects the size homogeneity of the droplets in the bulk ME.

The rheological behavior of the MJ-loaded and MJunloaded formulations was evaluated by testing flow. The flow curves revealed that all ME systems showed a nonlinear relationship between the shear stress $(\tau)$ and the shear rate $(\gamma)$, which is characteristic of a non-Newtonian flux material (Figure 3). The influence of the $\mathrm{O} / \mathrm{S}$ ratio on the rheological

Table 2 Droplet size and polydispersity index of the MEs determined by light scattering

\begin{tabular}{|c|c|c|c|c|c|c|c|}
\hline \multirow[t]{2}{*}{ ME } & \multirow[t]{2}{*}{ O:S ratio } & \multicolumn{3}{|l|}{ MJ-unloaded } & \multicolumn{3}{|l|}{ MJ-loaded } \\
\hline & & Diameter (nm) & SD & PDI & Diameter $(\mathrm{nm})$ & SD & PDI \\
\hline$A$ & 0.1 & 168.0 & 0.255 & 0.246 & 56.8 & 0.398 & 0.197 \\
\hline B & 0.2 & 181.1 & 0.142 & 0.324 & 64.9 & 0.432 & 0.244 \\
\hline C & 0.3 & 138.9 & 0.454 & $0.34 I$ & 82.2 & 0.213 & 0.255 \\
\hline $\mathrm{D}$ & 0.4 & 80.1 & 0.197 & 0.276 & 36.7 & 0.125 & 0.272 \\
\hline $\mathrm{E}$ & 0.5 & 47.4 & 0.317 & 0.316 & 11.6 & 0.113 & 0.073 \\
\hline
\end{tabular}

Abbreviations: ME, microemulsion; MJ, methyl dihydrojasmonate; S, surfactant; O, oil phase; PDI, polydispersity index; SD, standard deviation. 


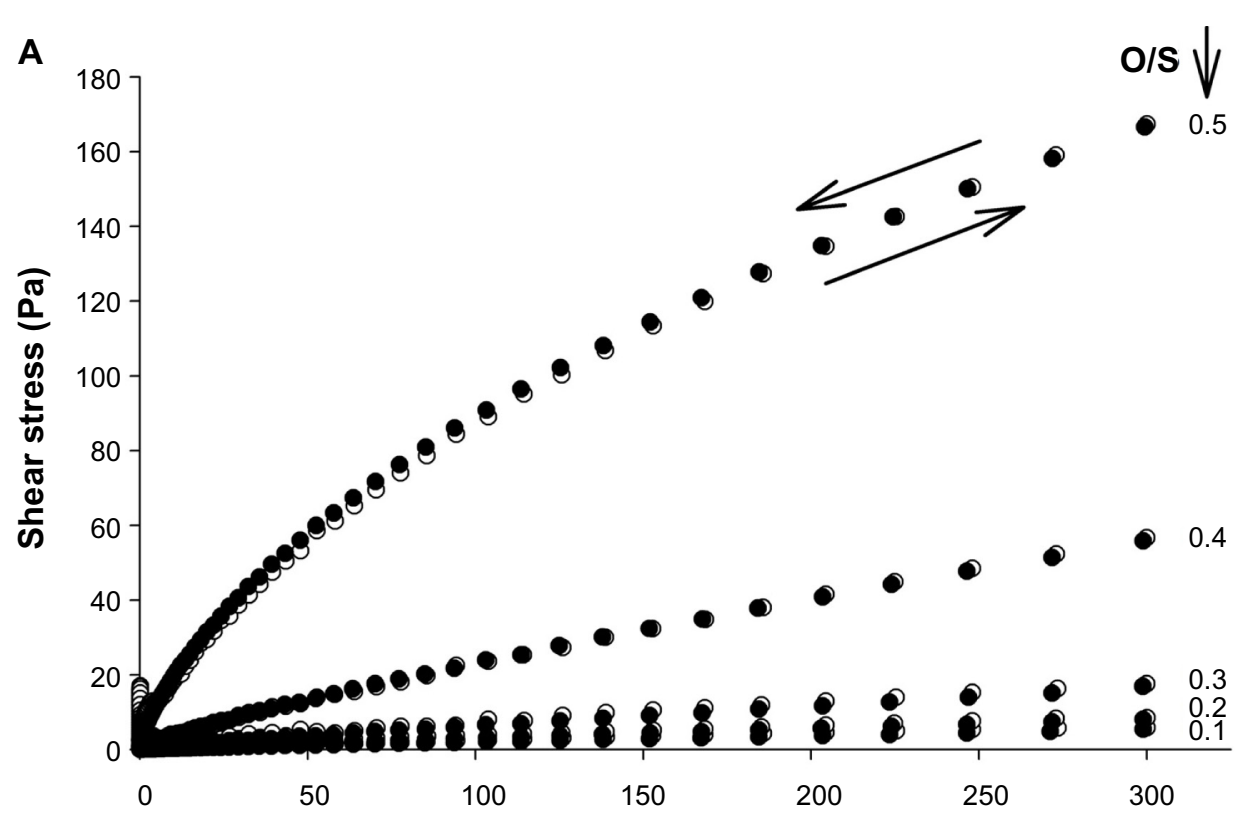

Shear rate $\left(\mathbf{s}^{-1}\right)$

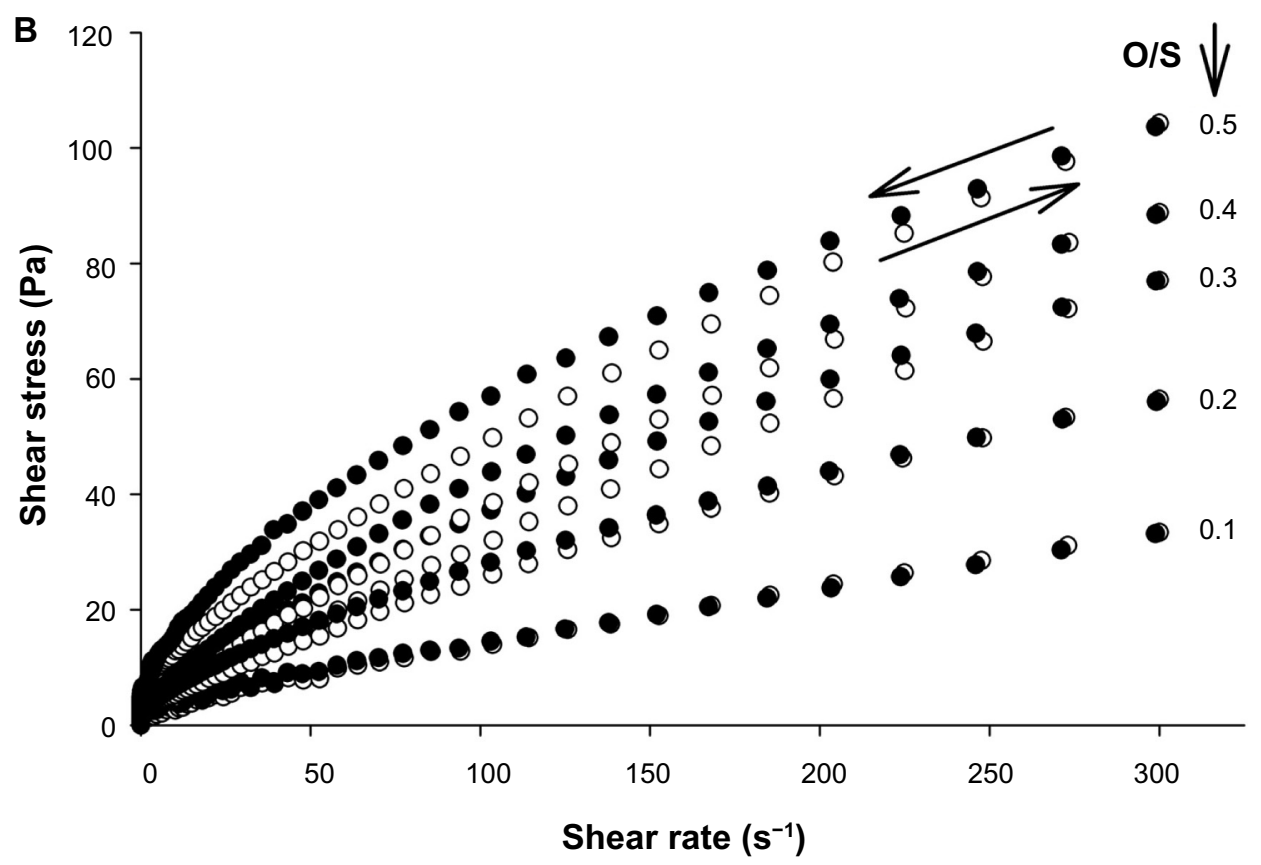

Figure 3 Rheological behavior of ME stabilized with PC/EU/SO.

Notes: (A) MJ-unloaded ME; (B) MJ-loaded ME, $25^{\circ} \mathrm{C}$.

Abbreviations: MJ, methyl dihydrojasmonate; ME, microemulsion; PC, phosphatidylcholine; EU, Eumulgin ${ }^{\circledR}$ HRE 40; SO, sodium oleate; O/S, oil phase/surfactant.

behavior of MEs in the absence and presence of the drug, respectively, is shown in Figure 3A and B.

The data from Figure 3A reveal that for MJ-unloaded MEs, the thixotropic response was negligible for all $\mathrm{O} / \mathrm{S}$ ratios. This is a characteristic phenomenon of systems with fast recovery of their microstructure, which behaves as a time-independent structure with the upward and the downward curves overlapped. This behavior was especially more characteristic at low $\mathrm{O} / \mathrm{S}$ values, with a slight trend of antithixotropic behavior toward high values of $\mathrm{O} / \mathrm{S}$ ratio in which the proportion of the oil phase was more expressive.

A strong dependence on the microstructure organization of the MJ-loaded ME related to $\mathrm{O} / \mathrm{S}$ ratio was found (Figure 3B). Although at low $\mathrm{O} / \mathrm{S}$ ratios the microstructure recovery appears to be time-independent, above an $\mathrm{O} / \mathrm{S}$ ratio of 0.2 a clear antithixotropic behavior was revealed within the tested experimental limits. On the other hand, the proportion of oil-phase entrapment into the systems increases with the 
$\mathrm{O} / \mathrm{S}$ ratio. This phenomenon demonstrates the fundamental role of the oil phase for the existence of thixotropy. In this case, the increase in the shear rate during the rheology analysis induced the formation of new structures that temporarily modified the apparent viscosity of the system, thus providing conditions for the appearance of thixotropy.

In contrast, it is interesting to note that the incorporation of $\mathrm{MJ}$ into the ME produced a significant reduction in the shear-rate response, induced by the shear stress, for all $\mathrm{O} / \mathrm{S}$ values (Figure 3). This phenomenon may be related to the intense reduction in the droplet size in the presence of $\mathrm{MJ}$, which possesses a diffusion coefficient higher than the larger oil droplets. Thus, the drug incorporation into ME favored the organization of the internal microstructure of the system, allowing the maintenance of the rheological characteristics by reducing the size of the oil droplets.

The ME systems showed a nonlinear relationship between shear stress and shear rate, exhibiting a non-Newtonian profile. In this case, the viscosity is dependent on the shear rate, pressure, temperature, and time. ${ }^{3,28,29}$ Because of these properties, the systems behave as pseudoplastic ones, and a power-law model can be used to describe the flow characteristics of the MEs. Thus, the flow behavior can be described by the expression: ${ }^{30}$

$$
\tau=k(\gamma)^{n}
$$

where $k$ is a constant parameter related to the viscosity (consistency index) and $n$ is the flow-behavior index. In this model, $n>1$ represents a dilatant fluid, $n<1$ represents a pseudoplastic fluid, and Newtonian fluids have an $n$-value of unity. Table 3 gives the values of $k$ and $n$ for both MJ-loaded and MJ-unloaded MEs, and the variation of consistency index and $\mathrm{O} / \mathrm{S}$ values is shown in Figure 4.

The results in Table 3 show that all $n$-values obtained were less than a unity, indicating that these systems behave as pseudoplastic shear-thinning fluids. This behavior may be due to breaking of the more organized structures, favoring

Table 3 Effect of the ME compositions on flow behavior and consistency

\begin{tabular}{llllll}
\hline $\begin{array}{l}\text { MJ- } \\
\text { unloaded }\end{array}$ & $\boldsymbol{n}$ & $\begin{array}{l}\boldsymbol{\kappa} \\
\text { (Pa second) }\end{array}$ & $\begin{array}{l}\text { MJ- } \\
\text { loaded }\end{array}$ & $\boldsymbol{n}$ & $\begin{array}{l}\boldsymbol{\kappa} \\
\text { (Pa second) }\end{array}$ \\
\hline A & 0.84 & 0.05 & $\mathrm{~A}$ & 0.64 & 0.77 \\
B & 0.77 & 0.10 & $\mathrm{~B}$ & 0.80 & 0.78 \\
C & 0.67 & 0.35 & $\mathrm{C}$ & 0.78 & 1.03 \\
D & 0.79 & 0.61 & $\mathrm{D}$ & 0.69 & 1.05 \\
E & 0.60 & 5.35 & $\mathrm{E}$ & 0.60 & $3.1 \mathrm{I}$ \\
\hline
\end{tabular}

Abbreviations: ME, microemulsion; MJ, methyl dihydrojasmonate. the formation of less organized structures such as droplets when the shear rate is applied to the samples. As can be seen, $n$-values decrease with the increase in $\mathrm{O} / \mathrm{S}$ ratios, showing a trend of increasing the shear thinning characteristic of the studied systems. For MJ-loaded and MJ-unloaded MEs, the values of $k$ varied slightly at low $\mathrm{O} / \mathrm{S}$ ratios (Table 3 ). Analysis of the results of Figure 4 indicated that the consistency index varied slightly upward to $0.4(\mathrm{O} / \mathrm{S}$ ratio), but increased abruptly at a higher ratio (0.5). The increase of the oil phase leads to an enhancement of the consistency index. The apparent viscosity of the ME is directly related to the consistency index, which is measured directly from the slope of the rheological curves. Then, with the increase in the $\mathrm{O} / \mathrm{S}$ ratio, a higher apparent viscosity of MEs was obtained.

The effect of the $\mathrm{O} / \mathrm{S}$ ratio for both MJ-unloaded and MJ-loaded MEs was also analyzed by polarized light microscopy, and the results are shown in the photomicrographs of Figure 5. In the absence of $\mathrm{MJ}$, a negligible presence of Maltese crosses could be verified at up to $\mathrm{O} / \mathrm{S}$ ratio values of 0.4 , indicating that in these conditions the systems behaved with isotropic characteristics and did not divert the plane of polarized light (Figure 5A). However, when the O/S ratio was increased to 0.5 , a large number of Maltese cross-structures could be observed, indicating an increase in the structural organization of the system and suggesting the presence of lamellar phases.

For MJ-loaded MEs, a complete isotropy with a clear system was obtained at a low $\mathrm{O} / \mathrm{S}$ ratio. For MEs prepared with an $\mathrm{O} / \mathrm{S}$ ratio up to 0.2 , isotropic behavior, characterized by a dark field, was obtained. This profile data for systems obtained from a mixture of surfactant/water/oil phase can be attributed to the formation of both oil-nanodroplet dispersion and cubic liquid-crystalline arrangement. However, the liquid characteristic for the system verified in the pseudo-ternary phase diagram, showing low apparent viscosity, allows us to describe the system as dispersed droplets, as previously described in the literature. ${ }^{8,31}$ On the other hand, for MEs with $\mathrm{O} / \mathrm{S}$ ratios above 0.2 , the data of the photomicrographs revealed significant differences when compared with low$\mathrm{O} / \mathrm{S}$-ratio MEs. The presence of Maltese crosses (Figure 5B), which are characteristic of lamellar arrangements, was verified, demonstrating the effect of the predominance of the oil-phase effect over the surfactant effect on the structural organization of the MEs. However, even at $\mathrm{O} / \mathrm{S}$ ratio values higher than 0.5 , the systems still exhibited characteristics of nonviscous fluid.

In order to further determine the crystalline degree of the studied systems, the X-ray diffraction patterns for both 


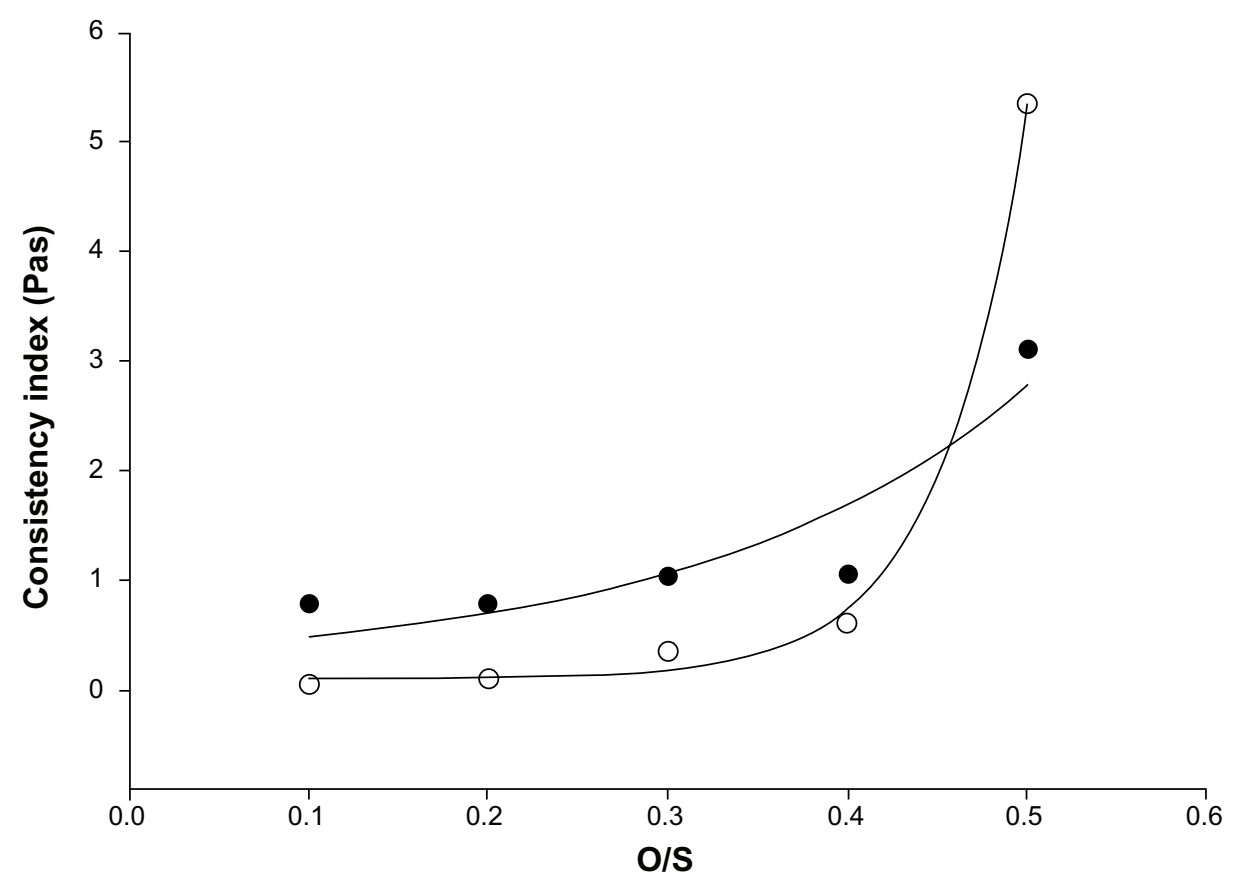

Figure 4 Effect of the oil phase/surfactant ratio on the consistency index of the system.

Notes: •, MJ-loaded ME; O, MJ-unloaded ME, $25^{\circ} \mathrm{C}$.

Abbreviations: $\mathrm{MJ}$, methyl dihydrojasmonate; $\mathrm{ME}$, microemulsion; $\mathrm{O} / \mathrm{S}$, oil phase/surfactant.

the formulation components and the structured MEs were determined and compared with each other (Figure 6). This procedure may provide information on the relative contributions of the components in the final formulations.

Especially for injectable ME, it is very important to know whether such systems are either amorphous or crystalline regarding the incorporation of $\mathrm{MJ}$ into the MEs by the effect of varying the proportion of the oil phase or surfactant.
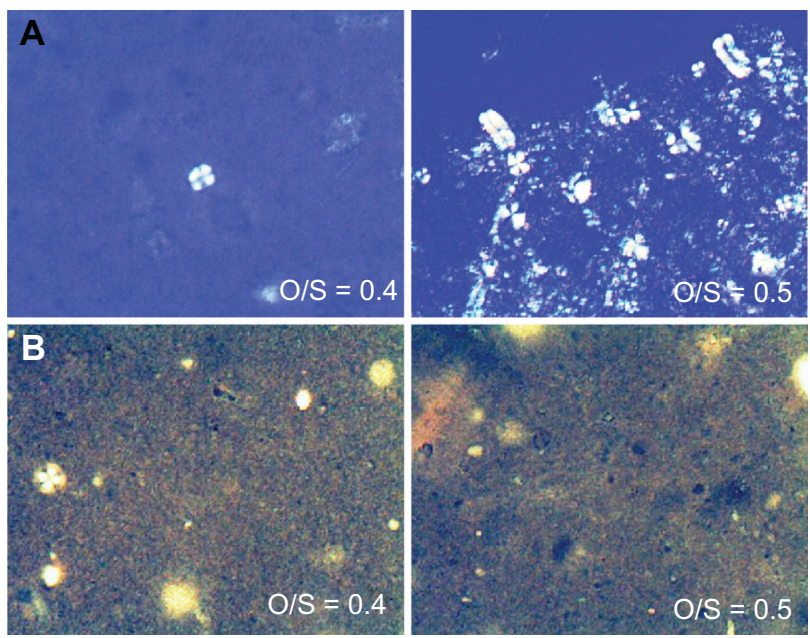

Figure 5 Polarized light microscopy of the ME stabilized with PC/EU/SO. Notes: (A) MJ-unloaded; (B) MJ-loaded ME.

Abbreviations: MJ, methyl dihydrojasmonate; ME, microemulsion; PC, phosphatidylcholine; EU, Eumulgin ${ }^{\circledR}$ HRE 40; SO, sodium oleate; O/S, oil phase/surfactant.
The data of X-ray diffractions obtained from MJ-unloaded and MJ-loaded MEs and their components (EU, PC, SO, and $\mathrm{CHO}$ ) are shown in Figure 6.

For both MJ-unloaded and MJ-loaded MEs, the effect of the $\mathrm{O} / \mathrm{S}$ ratio on $\mathrm{X}$-ray diffractometry is shown in Figure 6A and $\mathrm{B}$, respectively. It was verified that independently of the $\mathrm{O} / \mathrm{S}$ ratio, all samples exhibited a large low-intensity peak of amorphous structure. Although the samples remained amorphous mainly for the MJ-loaded samples, the increase in the $\mathrm{O} / \mathrm{S}$ ratio led to more intense peaks in the diffractograms (Figure 6B). This can be explained by the fact that the $\mathrm{CHO}$ has crystalline characteristics, and the increase in the $\mathrm{O} / \mathrm{S}$ ratio allows the decrease in the amorphous properties in the ME formulations. It can be seen that the incorporation of the liquid lipophilic MJ also favors the increase in the amorphousness of the samples. In fact, the data of Figure 6D reveal this trend, demonstrating the effect of the contribution of MJ proportions on the amorphous property of the systems.

The diffractograms of Figure $6 \mathrm{C}$ obtained for the oilphase $\mathrm{CHO}$ show an intense and well-defined diffraction peak that is characteristic of crystalline structures. However, the $\mathrm{SO}$, a component of the surfactant mixture, has a predominant amorphous profile, and a negligible crystalline characteristic signal was exhibited in the diffractograms. The surfactants PC and EU, as expected, showed an attenuated and broad 
A

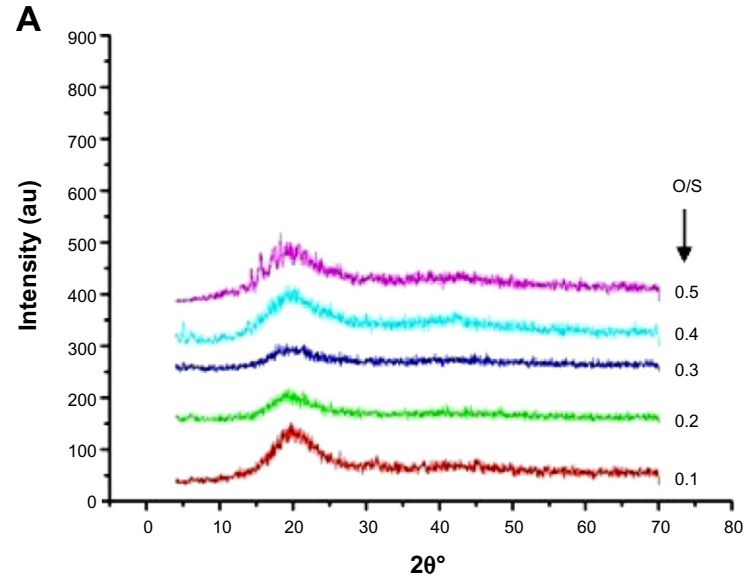

C

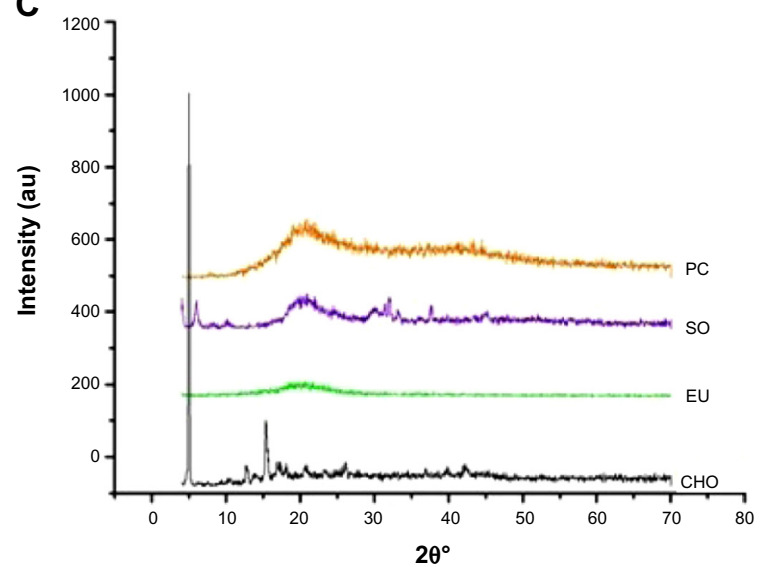

B

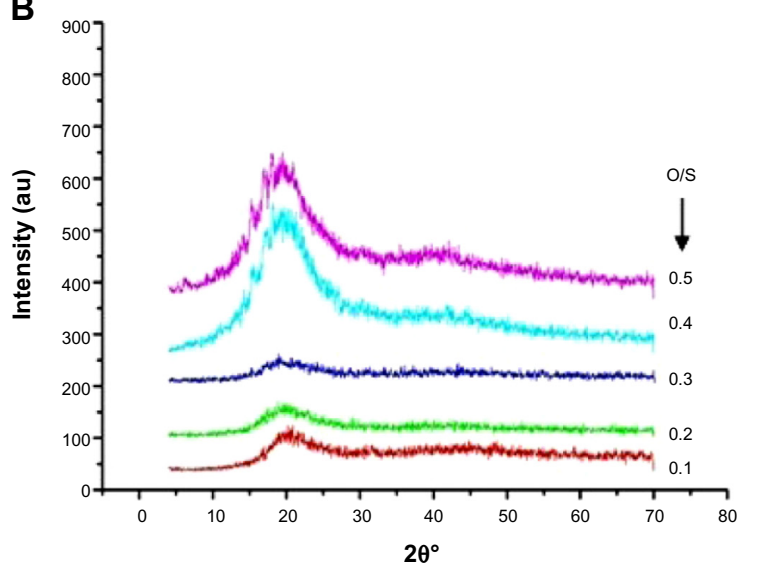

D

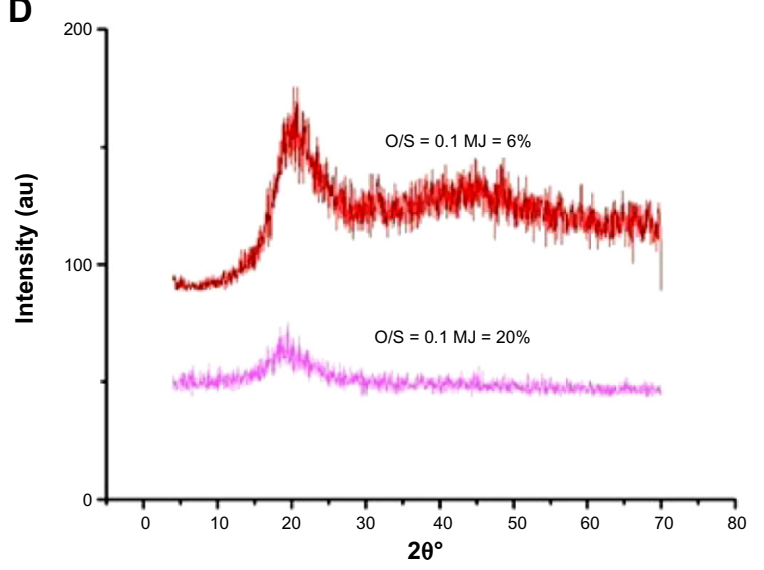

Figure 6 X-ray diffractograms for pure substances and the formulations stabilized with PC/EU/SO.

Notes: (A) MJ-unloaded ME; (B) MJ-loaded ME; (C) pure substances; (D) MJ variation.

Abbreviations: MJ, methyl dihydrojasmonate; ME, microemulsion; PC, phosphatidylcholine; EU, Eumulgin ${ }^{\circledR}$ HRE 40; SO, sodium oleate; $\mathrm{CHO}$, cholesterol; O/S, oil phase/ surfactant.

peak, which is a common feature of amorphous structures (Figure 6C).

This set of data associated with the character of the liquid lipophilic antitumor drug reveals the predominant characteristic of amorphous MEs of this study, a profile that is very common and desirable for injectable emulsion systems.

\section{Conclusion}

This study demonstrated that it is possible to obtain nanosized structures stabilized by a mixture of soy $\mathrm{PC} / \mathrm{SO} /$ polyoxyethylene glycerol tri-hydroxystearate 40 surfactants prepared by ultrasonic irradiation. The pseudo-ternary phase diagram shows that the region of interest, LME, was formed by proportions larger than $60 \%$ of water. By increasing the oil phase and surfactants, gel-emulsion regions were formed. All the studied systems presented a pseudoplastic shear-thinning fluid behavior and structure with amorphous characteristics. Droplet size was directly dependent on the $\mathrm{O} / \mathrm{S}$ ratio and the MJ incorporation. Although most of the MJ-unloaded systems showed anisotropic characteristics, in the presence of MJ the isotropic characteristic was predominant. It was possible to conclude that these systems can be used as a drug carrier for $\mathrm{MJ}$ administration.

\section{Acknowledgments}

The authors gratefully acknowledge the Coordenação de Aperfeiçoamento de Pessoal de Nível Superior (CAPES) and the Conselho Nacional de Desenvolvimento Científico e Tecnologico (CNPq) for financial support, and Glenn Hawes, MEd, from the University of Georgia, for editing this manuscript.

\section{Disclosure}

The authors report no conflicts of interest in this work.

\section{References}

1. Formariz TP, Sarmento VHV, Silva-Junior AA, Scarpa MV, Santilli CV, Oliveira AG. Doxorubicin biocompatible O/W microemulsion stabilized by mixed surfactant containing soya phosphatidylcholine. Colloids Surf B Biointerfaces. 2006;51:54-61. 
2. Formariz TP, Urban MCC, Silva-Júnior AA, Gremião MD, Oliveira AG. Microemulsões e fases líquidas cristalinas como sistemas de liberação de fármacos. Braz J Pharm Sci. 2005;41:301-313.

3. Oliveira AG, Chiavacci LA, Scarpa MV, Egito EST. Microemulsions: physico-chemical approaches on the system for pharmaceutical applications. In: Li SJ, editor. Current Focus on Colloids and Surfaces. Kerala, India: Transworld Research Network; 2009:57-84.

4. Lawrence MJ, Rees GD. Microemulsion-based media as novel drug delivery systems. Adv Drug Deliv Rev. 2000;45:89-121.

5. Correa MA, Scarpa MV, Franzini MC, Oliveira AG. On the incorporation of the non-steroidal anti-inflammatory naproxen into cationic $\mathrm{O} / \mathrm{W}$ microemulsions. Colloids Surf B Biointerfaces. 2005;43:108-114.

6. Pestana KC, Formariz TP, Franzini CM, et al. Oil-in-water lecithinbased microemulsions as a potential delivery system for amphotericin. Colloids Surf B Biointerfaces. 2008;66:253-259.

7. Formariz TP, Chiavacci LA, Sarmento VHV, Santilli CV, Tabosa do Egito ES, Oliveira AG. Relationship between structural features and in vitro release of doxorubicin from biocompatible anionic microemulsion. Colloids Surf B Biointerfaces. 2007;60:28-35.

8. Formariz TP, Chiavacci LA, Sarmento VHV, et al. Structural changes of biocompatible neutral microemulsions stabilized by mixed surfactant containing soya phosphatidilcholine and their relationhship with doxorubicin release. Colloids Surf B Biointerfaces. 2008;63:287-295.

9. Franzini MC, Pestana KC, Molina EF, Scarpa MV, Egito EST, Oliveira AG. Structural properties induced by the composition of biocompatible phospholipid-based microemulsion and amphotericin B association. J Biomed Nanotech. 2012;8:350-359.

10. Assumpção JUCV, Campos ML, Nogueira Filho MAF, et al. Biocompatible microemulsion modifies the pharmacokinetic profile and cardiotoxicity of doxorubicin. J Pharm Sci. 2013;102:289-296.

11. Farmer EE, Ryan CA. Interplant communication: air-borne methyl jasmonate induces synthesis of proteinase inhibitors in plant leaves. Proc Natl Acad Sci U S A. 1990;87:7713-7716.

12. Yeruva L, Elegbede JA, Carper SW. Methyl jasmonate decreases membrane fluidity and induces apoptosis via tumor necrosis factor receptor 1 in breast cancer cells. Anticancer Drugs. 2008;19:766-776.

13. Conti M. Cyclopentenone: a special moiety for anticancer drug design. Anticancer Drugs. 2006;17:1017-1022.

14. Avanci NC, Luche DD, Goldman GH, Goldman MHS. Jasmonates are phytohormones with multiple functions, including plant defense and reproduction. Genet Mol Res. 2010;9:484-505.

15. Flescher E. Jasmonates in cancer therapy. Cancer Lett. 2007;245:1-10.

16. Fingrut $\mathrm{O}$, Reischer $\mathrm{D}$, Rotem $\mathrm{R}$, et al. Jasmonates induce nonapoptotic death in high-resistance mutant p53-expressing B-lymphoma cells. $\mathrm{Br}$ J Pharmacol. 2005;146:800-808.
17. Cohen E, Flescher E. Methyl jasmonate: a plant stress hormone as an anti-cancer drug. Phytochemistry. 2009;70:1600-1609.

18. Rotem R, Heyfets A, Fingrut O, Blickstein D, Shaklai M, Flescher E. Jasmonates: novel anticancer agents acting directly and selectively on human cancer cell mitochondria. Cancer Res. 2005;65:1984-1993.

19. Kim JH, Lee JY, Oh SY, et al. Methyl jasmonate induces apoptosis through induction of Bax/Bcl-XS and activation of caspase-3 via ROS production in A549 cells. Oncol Rep. 2004;12:1233-1238.

20. Reischer D, Heyfets A, Shimony S, Nordenberg J, Kashman Y, Flescher E. Effects of natural and novel synthetic jasmonates in experimental metastatic melanoma. Br J Pharmacol. 2007;150:739-749.

21. Oliveira AG, Rossanezzi G, Formariz TP, Egito EST, Scarpa MV. Effect of cationic micelles on the decomposition of alpha-aminophenyl cephalosporins. Colloids Surf B Biointerfaces. 2010;79:372-376.

22. Oliveira AG, Scarpa MV, Chaimovich H. Effect of hexadecyltrimethylammonium bromide-based microemulsions on the rate of decomposition of the beta-lactam antibiotic cephaclor. J Pharm Sci. 1997;86: 616-620.

23. Kumar R, Katare OP. Lecithin organogels as a potential phospholipidstructured system for topical drug delivery: a review. AAPS Pharm Sci Tech. 2005;6:298-310.

24. Trotta M, Pattarino F, Ignono T. Stability of frug carrier emulsions containing phosphatidylcholine mixtures. Eur J Pharm Biopharm. 2002;53:203-208.

25. Trotta M. Influence of phase transformation on indomethacin release from microemulsions. J Control Release. 1999;60:399-405.

26. Oliveira AG, Nothenberg MS, Cuccovia IM, Chaimovich H. Micellar catalysis of the intramolecular aminolysis of the $\beta$-lactam antibiotic cephaclor. J Phys Org Chem. 1991;4:19-24.

27. Schreier S, Malheiros SV, Paula E. Surface active drugs: self-association and interaction with membranes and surfactants. Physicochemical and biological aspects. Biochim Biophys Acta. 2000;1508:210-234.

28. Formariz TP, Wanczinski BJ, Júnior-Silva AA, Scarpa MV, Oliveira AG. Biotecnologia de sistemas coloidais aplicável na otimização do efeito terapêutico de fármacos usados no tratamento do câncer. Infarma. 2004;16:44-57.

29. Atkinson HV. Modeling the semisolid processing of metallic alloys. Prog Mater Sci. 2005;50:341-412.

30. Chen ZQ, Dai ZG. Colloid Chemistry. Beijing: Higher Education Press; 1984

31. Gabboun NH, Najib NM, Ibrahim HG, Assaf S. Release of salicylic acid, diclofenac acid and diclofenac acid salts from isotropic and anisotropic nonionic surfactant systems across rat skin. Int $J$ Pharm. 2001;212:73-80.
International Journal of Nanomedicine

\section{Publish your work in this journal}

The International Journal of Nanomedicine is an international, peerreviewed journal focusing on the application of nanotechnology in diagnostics, therapeutics, and drug delivery systems throughout the biomedical field. This journal is indexed on PubMed Central, MedLine, CAS, SciSearch $\AA$, Current Contents $₫ /$ Clinical Medicine,

\section{Dovepress}

Journal Citation Reports/Science Edition, EMBase, Scopus and the Elsevier Bibliographic databases. The manuscript management system is completely online and includes a very quick and fair peer-review system, which is all easy to use. Visit http://www.dovepress.com/ testimonials.php to read real quotes from published authors. 